S atentados terroristas aos EUA sinalizaram para possíveis alterações na geopolítica mundial, com forte impacto sobre a economia do planeta. Para analisar as conseqüências político-econômicas do episódio e as perspectivas para a Amércia Latina, Mercosul e Brasil, Augusto Guzzo Revista Acadêmica ouviu o cientista político Rui Tavares Maluf, doutorando e mestre em Ciência Política, bacharel em Comunicação Social e professor do curso de Ciências Econômicas das Faculdades Integradas "Campos Salles".

A.G.R.A. - Após 1991, quando a União Soviética entrou em colapso, imaginava-se que seria estruturada uma "nova ordem mundial", cujas bases seriam a democracia liberal. Alguns intelectuais, como Francis Fukuyama, chegaram a decretar o fim da História. Passados 10 anos, estamos assistindo a um recrudescimento da insegurança, tal como evidenciam os atentados ao World Trade Center e ao Pentágono. Estamos a caminho de uma nova polaridade mundial, não ligada a disputas ideológicas, mas a questões religiosas ou étnicas? A democracia como valor universal corre o risco de não sobreviver?

Rui - Em primeiro lugar, gostaria de expressar minha convicção de que uma efetiva análise sobre a política internacional (e a economia aí incluída) é sempre uma aproximação muito imperfeita dos acontecimentos. Afirmo isto na medida em que o mundo é bem mais complexo do que desejamos admitir e, portanto, muito mais difícil para se fazer asserções de caráter global. Feita esta ressalva, penso que, após o cólapso do bloco soviético deparamos-nos com uma situação muito desconfortável, que foi a do nascimento de vários estados a partir dos escombros do extinto regime comunista, os quais pareciam - em sua maioria - reunir a um só tempo uma população irada com tudo o que lembrasse a ex-União Soviética, pouca capacidade de integração econômica rápida com os países do bloco ocidental, devido a enorme desigualdade de desenvolvimento, ressurgimento da religiosidade com toda sua força, dificuldade de construção de um sistema democrático e ausência de uma visão e de ações coordenadas dos EUA e da União Européia (UE) para esses países. Portanto, a nova ordem mundial começou a se delinear no início dos anos 90 , com a supremacia econômica e militar dos EUA, e sem que houvesse outra força a eles equiparável que pudesse oferecer ao menos uma alternativa no plano de valores fundamentais. A República Popular da China não ocupou o lugar da URSS no cenário internacional como contraponto aos EUA e a UE, por sua vez, não parece ter esta vocação, apesar de não endossar toda política norte-americana, pois carece de agenda própria para ter um curso nítido e coeso de ações para o mundo. Quanto à democracia como valor universal, é importante ressaltar que muitos países do mundo, especialmente do Oriente, não a têm como um valor para si. Portanto, a democracia ainda não tem - a meu juízo - um sentido universal. É bem verdade, porém, que democracia vem sendo uma palavra cada vez mais pronunciada, mesmo por governantes que não a defendem, podendo, a longo prazo, tornar-se, sim, um bem universal. Não obstante, no curto prazo, os atentados ao World Trade Center e ao Pentágono (bem como seus desdobramentos de curto prazo) deverão gerar o seguinte impasse: ou o projeto democrático universal sofre uma freada temporária, ou se expande com mais vigor ainda.

A.G.R.A. - Diante deste quadro de instabilidade mundial, quais são as ameaças políticas que pairam sobre o Brasil?

Rui - Se é factível falar em grandes ameaças políticas para o Brasil decorrentes da instabilidade mundial, estas, em tese, estariam vinculadas a um quadro de profunda e duradoura recessão econômica mundial. Mas isto precisaria se dar simultaneamente à eleição de um governo (presidente e Congresso) sem maioria coesa e que se propusesse 
a mudar o cerne da política econômica. Tudo isso acoplado a uma futura oposição parlamentar que de forma deliberada atuasse para fraturar a espinha dorsal do governo. Não acredito que esta combinação de fatores esteja no horizonte visível.

A.G.R.A. - Esta nova conjuntura pode inviabilizar os processos de integração regional? Como o Mercosul pode enfrentar a este mundo cheio de riscos?

Rui - Realmente, o Mercosul vive um quadro de muita dificuldade, devido a mútua alimentação de questões estruturais e conjunturais. No plano estrutural está a desigualdade econômica, social e demográfica entre seus quatro membros (Argentina, Brasil, Paraguai e Uruguai). No plano conjuntural, está a diferença de políticas cambiais dos dois maiores parceiros - Argentina e Brasil - sendo que o primeiro enfrenta uma aguda crise política e econômica. Ainda assim, parece-me que os principais formuladores políticos deste bloco reconhecem que o fim do Mercosul seria pior para todos. Desse modo, o único modo deste bloco enfrentar este mundo "cheio de riscos", como vocês me perguntam, é se fortalecendo e não com indiferença quanto a sua sorte. Mais: todo e qualquer ingresso na ALCA passa pelo próprio fortalecimento do Mercosul e não ao contrário. E estou convencido de que o Brasil tem sido o parceiro que mais aposta na sua manutenção e no seu fortalecimento.

A.G.R.A. - Especificamente quanto à Argentina, a perspectiva de abandono da paridade fixa dólar-peso pode acelerar a crise política e social? Como a sociedade civil argentina tem se portado frente à crise econômica que se estende desde 1998?

Rui - Acho que a crise Argentina é, antes de mais nada, política, nascida de uma aliança eleitoral (UCR-Frepaso), cuja força se estruturou em ser contra o governô Menem, mas sem ter coesão e identidade suficientes para a adoção de medidas político-econômico-administrativas eleitoralmente custosas. Além disso, a aliança não contava com maioria parlamentar suficiente que prescindisse de exaustivas negociações. Esta minoria ficou ainda menor com a eleição de 14 de outubro passado, pois ambos partidos da coligação perderam cadeiras no Parlamento (Câmara e Senado), além de terem concorrido separadamente em algumas localidades como na Capital Federal. Sobre a falta de coesão, basta lembrar dois casos: a renúncia do vice-presidente Carlos Chacho Álvares (Frepaso) que, a meu ver, revelou a absoluta ausência de responsabilidade de um líder político e a nomeação do seu adversário Domingos Cavallo para o Ministério da Economia. A nomeação de Cavallo passou pela necessidade de contar com um nome de confiança para o mercado, ao mesmo tempo que aumentasse a sustentação parlamentar do governo, carreando alguns votos de parlamentares de seu partido Aliança pela República. A postura de Álvares pode ter sido ótima para sua coerência pessoal e sua liderança partidária, mas péssima para a sustentação do governo, deixando o presidente De La Rúa com pouquíssima margem de manobra. Portanto, com o resultado eleitoral, a situação política deverá ficar ainda mais difícil, pois a tendência é de que o Partido Justicialista (PJ) se sinta mais fortalecido, vindo a "cooperar" mais com a sustentação do governo do que a própria Frepaso, embora sob uma ótica de seu interesse eleitoral para a próxima eleição presidencial. No que diz respeito, especificamente, à paridade dólar-peso, até agora ainda conta com expressivo apoio popular. Porém, um estudo recente revelou que seu abandono seria custoso mas não desastroso para a economia como um todo, pois o nível e o perfil do endividamento em dólar seria menor do que o imaginado. Finalmente, quando comparado ao Brasil, considero os conflitos internos da Argentina sempre muito intensos e difíceis de encontrarem o ponto de distensão e/ou superação necessários para o sistema democrático funcionar com estabilidade. Isto explica, em certa medida, porque nosso parceiro e vizinho rivalizou com a Bolívia em golpes de estado depois da independência. Mas isto não me leva a imaginar uma quebra do regime democrático.

A.G.R.A. - Estamos aqui no Brasil às vésperas do processo eleitoral. Diante do quadro políticopartidário atual e dos recentes acontecimentos mundiais, que tipo de projeto econômico podemos vislumbrar?

Rui - $\bigcirc$ principal partido de oposição ao atual governo, o PT, já tem sido mais cauteloso em seus pronunciamentos sobre temas econômicos. Isto 
não quer dizer, é claro, que o PT não tenha sérios problemas internos entre uma ala minoritária mais à esquerda - mas bem representativa - e uma maioria não tão maior porém reformista. E, se o PSDB e PFL vierem a se tornar oposição a um eventual governo do PT, seriam mais cuidadosos no posicionamento em relação às matérias que possam significar vulnerabilidade para o Brasil. A própria experiência de governo exige isto. Contudo, deverá haver certa dificuldade, caso Ciro Gomes ou Antony Garotinho vençam a eleição. Para ficar apenas no primeiro, mais bem colocado nas pesquisas de intenção de voto, a trajetória dele é toda calcada sobre o personalismo, frases de efeito que tratam o adversário como demônio e reduzem a ação governamental ao voluntarismo, como se tudo se tratasse da boa ou má vontade do governante, ou do bom ou mau caráter do mesmo.

A.G.R.A. - Vimos em 1994 que a tônica da campanha eleitoral foi a estabilidade monetária; em 1998, o desemprego. Qual será o eixo do discurso político das eleições de 2002? Quais serão os temas que mais empolgarão os eleitores?

Rui - A agenda político-eleitoral deverá estar pautada e interpenetrada por três dimensões; polí- tica econômica, política-social e ética. No campo econômico, a oposição deverá continuar a criticar o governo, especialmente no campo do programa da privatização, relacionando-o com a qualidade dos serviços pós-privatização. Diferentemente da última eleição, a oposição deverá atacar o Plano Real, mostrando que a parte central de sua conquista, a estabilização monetária, estaria por um fio. Certamente, o governo estará menos confortável neste item e procurará demostrar que as vicissitudes se devem mais à conjuntura internacional. De qualquer modo, a situação do País até o final do primeiro quadrimestre do próximo ano influenciará muito na definição dos itens principais da agenda político-eleitoral. No campo social, a oposição procurará enfatizar a responsabilidade do governo no crescimento do nível de desemprego e suas conseqüências em várias setores. Porém, o governo deverá apresentar resultados nos setores da saúde e da educação, especialmente avanços nas regiões mais afastadas dos grandes centros. Finalmente, na questão da ética, a oposição levantará todos os casos envolvendo os parlamentares da base de sustentação em casos de corrupção, para mostrar que isto só poderá ter um fim com uma mudança de governo. 


\section{Do transplante de órgãos}

I

A matéria relacionada ao transplante de órgãos envolve outras questões e tem abrangência bem maior do que a apresentada no título, estando disciplinada na Lei Federal n. 9.434, de 04.02.97, que dispõe sobre a remoção de órgãos, tecidos e partes do corpo humano para fins de transplante e tratamento, alterada pela Lei n. 10.211, de 23.03.2001 e regulamentada pelo Decreto n. 2.268, de 30.06.97.

\section{II}

Existem duas espécies daquela remoção: uma de partes (sentido lato) de corpo humano de pessoa morta, conhecida como disposição "post mortem", e outra de partes (sentido lato) de corpo humano vivo.

\section{III}

No primeiro caso, a retirada post mortem de tecidos, órgãos ou partes do corpo humano, para os fins citados, deverá ser precedida de diagnóstico de morte encefálica, atestada e registrada por dois médicos não participantes das equipes de remoção e transplante, obedecidos os critérios clínicos e tecnológicos definidos por resolução do Conselho Federal de Medicina, sendo admitida a presença de médico de confiança da família do falecido no ato da comprovação e da atestação do óbito declarado.

Esse procedimento dependerá de autorização do cônjuge ou parente, maior de idade, obedecida a linha sucessória, reta ou colateral, até o segundo grau inclusive, firmada em documento subscrito por duas testemunhas presentes à verificação da morte, a menos que na Carteira de Identidade Civil e na de Habilitação esteja expressamente consignada a doação de determinados tecidos, órgãos e partes do corpo feita pelo próprio doador, o que, todavia, pode ser reformulado a qualquer tempo, registrando-se no documento a nova declaração.

Já a remoção post mortem, quando se tratar de pessoa juridicamente incapaz, pela idade ou por doença, poderá ser feita desde que permitida, expressamente, por ambos os pais ou por seus responsáveis legais.

De outra parte, é vedada a remoção post mortem de tecidos, órgãos ou partes de pessoas não identificadas, devendo, no caso de morte sem assistência médica, de óbito em decorrência de causa mal definida ou de outras situações nas quais houver indicação de verificação da causa médica do falecimento, serem tomadas certas cautelas e mediante autorização do patalogista responsável.

Os beneficiários da remoção post mortem serão os que compuserem a lista de espera organizada por entidade do Serviço Nacional de Transplantes, SNT, como determinado no Decreto Federal n. 2.268, de 30.06.1997, que regulamentou a Lei n. 9.434, de 04.02.97, exceto quando, ainda vivo, alguém fizer, válida e regularmente, doação específica de seus órgãos para depois de sua morte, indicando pessoa certa e determinada como beneficiária, como sucede com a disposição em se tratando de corpo vivo.

Por fim, em atenção ao respeito para com o cadáver e para com a família, preceitua a lei que será ele "condignamente recomposto para ser entregue, em seguida, aos parentes do morto ou seus responsáveis legais para sepultamento".

IV

Com relação à disposição de tecidos, órgãos e

* Juiz titular do Tribunal de Alçada Criminal; juiz auxiliar da Corregedoria Geral da Justiça e da Presidência do Tribunal de Justiça do Estado de São Paulo; juiz de Direito substituto em diversas comarcas do interior e na Capital; promotor de Justiça; Advogado formado pela PUC-SP; integrante de Bancas de Concursos da Fundação Carlos Chagas para provimento de cargos do Ministério Público e da Magistratura. 